\title{
Cyphers: Hip-Hop and Improvisation
}

\section{Paul Watkins and Rebecca Caines}

The whole circumference is a protection, at the same time it's an expression, so the [cypher] circle is there and it seems to be almost claustrophobic, but everyone is free and they want to be tight like that, together like that. (Abiodun Oyowele qtd. in Freestyle: The Art of Rhyme)

Hip-hop music and culture is a chiaroscuro of social consciousness and mainstream commodification, a chameleonesque art form that adapts to every environment it encounters, a personal saviour and communitarian mobilizer born out of a disenfranchised youth movement in the post-industrial urban nightmare of America's neglected ghettos. ${ }^{1}$ Hip-hop's lineage of hagiography consists of graffiti writers, breakers, DJs, and emcees who animate the black postmodern ethos through raps that contain ad-lib logorrhea, near-assonance, and gritty vocab with gunfire punctuation, announcing with bravado to an oppressive white world that the carcinoid Other has adopted the master's tools and things will never be the same. Hip-hop music, like jazz, is an improvisational art form that draws from the long history of disenfranchised people repurposing the tools of the master to create new forms of art. ${ }^{2}$

To cypher is to rap, break, beatbox tightly together in a circle where each person just might get a moment in the spotlight. To cypher is to borrow and to lend, to playfully freewheel through whilst taking an exacting care for each word and carefully considering all the sounds, meanings, and interpretations. It is to fight back, to borrow, to steal, to represent, and to collaborate, whilst suddenly-surprisingly_at times aggressively claiming your own voice, your own right to speak. A cypher is a gathering of rappers, beatboxers, and/or breakers in a circle, extemporaneously making music together. In recent years, the cypher has also grown to include the crowd and spectators who are integral to maintaining the energy of a given cypher. In a cypher, one emcee will rap about a certain topic, which is quickly taken up or flipped by another emcee who plays off the prior words and themes. Each artist takes his or her respective turn, much like in a jazz solo. Cyphers flow freely between diverse performers who improvise their words, sounds, or movements to create a complex matrix of sharing. The circle can go on continuously, as long as emcees, beatboxers, dancers, and the crowd keep the fluidity of the cypher going. The cypher is welcoming and thus models a pedagogy that is inclusive and improvisational in nature.

This issue of Critical Studies in Improvisation/Études critiques en improvisation aims to act as a cypher, engaging with the embodied practice of locally specific yet globally implicated hip-hop, as we consider the cypher as a metaphor for the complexities of critically thinking about improvisation more broadly. Appropriately, our theme of "Cyphers" attracted a wide range of analyses with many points of intersection. Our final selection ranges from discussions with historically significant scholars and practitioners in hip-hop and Black expressive culture to newer texts at the intersections between hip-hop and other art forms, as well as those tracing the improvisatory affects of hip-hop across cultural and technological boundaries.

Rappers/emcees, b-boys and b-girls, graffiti artists, and DJs all make improvisatory real-time decisions, experiment with collaborative art, risk-take, and continually reconfigure ideas of "failure" and "mistake." Hip-hop scholarship intimates that creative improvisation in hip-hop is part of a wider field of social improvisation, acting as an expression of identity and culture as well as a practical toolkit for survival in dangerous conditions. As Mark Antony Neal reminds us, unplanned negotiations, creative and spontaneous problem solving hustles, and dialogues are activities that create options for survival and forms of social resistance (209). The mother of modern hip-hop scholarship, Tricia Rose (interviewed in this issue), suggests that the aesthetic (and we would argue, improvisatory) features of "flow," "layering," and "rupture" in hip-hop are tied to both creative and social outcomes. In Rose's analysis, hip-hop artists

create and sustain rhythmic motion, continuity, and circularity via flow: accumulate, reinforce, and embellish this continuity through layering; and manage threats to these narratives by building in ruptures that highlight the continuity as it momentarily challenges it. These effects at the level of style and aesthetics suggest affirmative ways in which profound social dislocation and rupture can be managed and perhaps contested in the cultural arena. Let us imagine these hip-hop principles as a blueprint for social resistance and affirmation; create sustaining narratives, accumulate them, layer, embellish, and transform them. However, be also prepared for rupture, find pleasure in it, in fact, plan on social rupture. When these ruptures occur, use them in creative ways that will prepare you for a future in which survival will demand a sudden shift in ground tactics. (39)

Nikki Giovanni (who got "Thug Life" tattooed on her arm in support of rapper 2Pac), also emphasizes how African Americans have turned survival into an improvisational aesthetic: "Style has a profound meaning to Black Americans [. . . ] If we can't have ham, we will boil chitterlings; if we are given rotten peaches, we will make cobblers; if given 
scraps, we will make quilts; take away our drums, and we will clap our hands. We prove the human spirit will prevail. We will take what we have to make what we need" (154-55). Despite the presence of this theme of improvisatory survival in many texts, improvisation remains only implicitly present in most hip-hop practice and scholarship. There has been very little in-depth, explicit attention paid to the exact relationship between improvisation and hip-hop. We hope this special issue will bring this connection into focus more and perhaps prompt new contributions to an ongoing cypher on this topic.

This issue is also inspired by the kind of "community" that forms and works through improvisation practices in hiphop. Disadvantaged communities across the world are utilizing the resistant history of African American, Hispanic, and Caribbean hip-hop forms as catalysts for locally-specific social and creative innovation. Tony Mitchell neatly summarizes the sheer range of different impulses that shape global hip-hop:

Japanese b-boys struggling with the hyperconsumerisim of Tokyo's youth culture, Italian posses promoting hardcore Marxist politics and alternative youth culture circuits, and Basque rappers using a punk rock-hip-hop syncretic to espouse their nationalist cause and promote the rights of ethnic minorities globally. Rappers in war-torn Bosnia declare their allegiance with Central Los Angeles and a rap group in Greenland protests that country's domination by the Danish language. (1)

Canadian scholar Charity Marsh (interviewed in this issue) reminds us, however, that each local community appropriates improvisatory hip-hop forms to match their own specific cultural and historical contexts, and these contexts, in turn, shape and affect how the improvising bodies perform and are received. Indigenous people in Canada, for example, have taken up hip-hop in complex, nuanced responses to the contemporary issues they face:

Similar to other musical genres that have been borrowed by Indigenous artists, this style of hip-hop combines local, cultural and regional elements with current global hip-hop forms and stylistic traits; but what makes it so interesting and provocative is that this new style of hip-hop allows for a rethinking of everyday life for young indigenous people living in Saskatchewan today.

Marsh suggests these practices allow young people to "express and make sense of present-day lived experiences, including the ongoing legacies of state enforced residential school programs and other practices of colonization, the current climate of contentious government initiated truth and reconciliation processes, and systemic issues of racism, poverty, and violence" ("Bits and Pieces of Truth," 346). Some hip-hop beats by Indigenous youth working in Marsh's IMP Labs are excerpted on the splash page for this issue.

In this issue, we also hope to highlight the complexities and layers that form in the hip-hop cypher. Hip-hop improvising is about connecting to hip-hop histories, respecting those who came before, and adapting wherever possible. Linguist Matt A. Foytin and his co-authors remind us that "Appropriating stylistic elements-patterns of rhyme, metaphors, or themes-from other rappers is perhaps the primary form of cultural transmission in the Hip-Hop Nation, the main way in which traditions are formed, ancestors are identified, and values passed on. Simple copying will be dismissed; artful borrowing and paying respect are highly regarded." Citing Mikhail Bakhtin, they suggest that "hip-hop artists 'rent words from the community' (Bakhtin) for the sake of constructing [their] own, personal utterance." Many cultural critics of rap and hip-hop culture also praise hip-hop music for its ability to function as a community consciousness-raising tool, citing black women, Aboriginal rappers, and/or LGBT rappers as nuanced figures who draw attention to racism, sexism, and other forms of oppression. On the other hand, media attention fixates on violence at rap concerts, the criminal use of samples, lurid fantasies of killing cops, homophobia or misogyny, and Black nationalism, often marring much more fruitful dialogues that should be happening.

The genre's various contradictions make hip-hop and rap music particularly ripe for scholarly analysis. In "The 1963 Hip-Hop Machine: Hip-Hop Pedagogy as Composition," Jeff Rice contends that we can venture to undertake critical projects grounded in the logic and style of hip-hop, citing projects, for example, that apply the notion of sampling (cut, paste, "whatever"). For Rice, the notion of the coincidental usage of "whatever" in hip-hop encompasses "an indifferent or oppositional student reaction to course demand" that arises out of cognitive dissonance (457). It is from this headspace of cognitive dissonance-the "whatever" (a student experience that cannot be named)—-that Rice suggests as an opportune moment for the "invention strategy for research-based argumentative writing" (453). Ultimately, hip-hop provides an understanding of how the process of sampling and remixing need not only apply to hip-hop. In fact, as a general methodology, hip-hop provides a framework for learning models that are more inclusive and improvisatory, demonstrating how sampling, juxtaposition, and marginalized viewpoints create opportune spaces to formulate new knowledge.

One area that we believe would be worthy of further research, but lies beyond the scope of this issue, is the specific role improvisation can play in education contexts. As Caines has argued, hip-hop in educational contexts requires a 
continual process of reconfiguring, of "finding new ways to accept the valuable 'gift of time' that improvised performance offers, to create live, unscripted moments in which new voices are heard and new histories are performed into being." Marc Lamont Hill's ethnographic work in classrooms has shown evocatively how hip-hop pedagogy can use hip-hop music, art, and dance as primary sources to teach interpretation and analytical thought to "create a space in which the literacy practices of the hip-hop community are moved from the margins to the center of the curriculum," as well as to "create a space for student voices to be heard in a way that validates their particular experiences and interests" (931). In the process of editing this issue, we were contacted by a number of inspiring artist/educator practitioners who are using hip-hop to teach in a range of areas including STEM subjects (Professor Lyrical), gender awareness, spirituality and social responsibility (Toni Blackman), performance and poetry (The BreakBeat Poets), and disability and difference (The Krip Hop movement, in particular the educational work of Leroy F. Moore, Jr., founder of the Krip Hop Nation). In Australia and Canada, hip-hop pedagogy continues to shape positive responses to social issues facing Indigenous youth and migrant communities (Marsh; Caines; Mitchell). We encourage you to follow the aforementioned links to websites where you can watch videos of these artist/educators in action.

There is systemic and deeply entrenched racism in North America-evident in the recent race "riots" and social unrest in Ferguson and Baltimore, the terrorist acts in Charleston, the all too frequent police brutality and racial profiling across the US, and (within a Canadian framework) the general invisibility of First Nations people, specifically the disappearance and murder of Indigenous women (Royal Canadian Mounted Police). It is fair to say that strategies to search for new ways of understanding the world and one another are desperately needed. Of course, those with the power to enact real change often disagree. The outgoing head of the Education Department in Arizona recently claimed that teaching hip-hop in public schools is illegal and dangerous, claiming "Public schools in Tucson, Arizona illegally promote ethnic solidarity and the overthrow of the U.S. government by teaching Mexican history, Rage Against the Machine lyrics and an explanation of hip-hop by rapper KRS-One" ("Teaching Hip-hop"). Clearly, there is still a long way to go before hip-hop's revolutionary promise is fulfilled.

Each paper in this issue addresses specific responses to the improvisatory impulse in hip-hop. We start the issue with a number of interviews. We are honoured that George Lipsitz agreed to interview Tricia Rose for this issue, bringing two significant scholars in Black Studies into conversation. This interview emphasizes Rose's vital contributions to the field of hip-hop scholarship and addresses the broader importance of improvisatory Black expressive cultural practices as "sites and sources of knowledges, as repositories of collective memory, as sights of moral instruction, as ways of calling communities into being through interaction and through performance." Rebecca Caines' interview with leading Canadian hip-hop researcher Charity Marsh focuses on Marsh's creation and leadership of the Interactive Media and Performance Labs in Saskatchewan as an innovative, exploratory space for disenfranchised communities to meet and learn about themselves through hip-hop practices. In conversation with Vancouver-based poet/scholar/DJ Wayde Compton, Paul Watkins addresses Compton's work on history, identity, and race, exploring the idea of improvising Blackness from within both local (BC) and transnational contexts. This audio interview is then remixed a number of times to allow the conversation to interact with Compton's readings of his own poetry and with a number of different music samples. Watkins then continues this exploration of critically engaged approaches to artistic practice with his review of Flying Lotus's (aka FlyLo, born Steven Ellison) 2014 release, "You're Dead!"

Jesse Stewart examines the form of "jazz-rap" that emerged in the 1980s and '90s. He charts the use of improvisational jazz forms in this type of hip-hop music and perceives this act as a kind of cultural memory practice that "mobilizes the musical past in the service of a socially progressive cultural politics of difference." Niel Scobie addresses dissonance and "noise" in improvisation and in hip-hop music, with special attention to the music of Public Enemy. For Scobie, "anti-musical" aesthetics allow the group to create lineage with the "discordant cries" of AfricanAmerican past practices whilst developing a potent improvisatory musical urgency and a call to arms.

Both Marcel Swiboda and Mark Campbell address technological mediation in hip-hop practices. Swiboda addresses "the break," developing a new critical history of electronic tools for beatmaking to supplement existing scholarship, which has tended to focus more on the use of turntables for isolating and manipulating the breakbeat. Swiboda suggests that technological and material histories of improvisatory beatmaking practices can be "technologically driven, idiomatically specific vernacular modes of critical knowledge practice" and can also bear an "intimate link to improvisatory practices." Campbell, on the other hand, focuses on current digital DJ practices. His ethnographic project is to discover how newer digital interfaces affect younger DJs in live performance and in radio settings. He argues that digital DJ interfaces might represent "ways to continue to humanize technology as a subversive afrosonic activity, while evolving the practice of DJing."

We would like to thank all of our contributors for joining with us in this cypher circle. We are particularly grateful for their patience with unavoidable delays regarding the publication of this issue. We would also like to thank our peer 
reviewers for their careful reading and advice to the authors. During the issue development, one editor and one staff member each successfully defended their PhD, two babies were born, and both editors took up academic positions in new cities. Our families supported us through these changes, as did the amazing journal staff and editorial board. We also would like to acknowledge the funding of the Social Sciences and Humanities Research Council, particularly the SSHRC funded International Institute for Critical Studies in Improvisation: a global network of scholars who continue to sustain and inspire us in our research into the critical, creative, and social potential of the improvisatory act.

\section{Notes}

${ }^{1}$ Throughout this issue, "Hip Hop" culture and "hip-hop" music style will be both denoted by the common spelling "hip-hop" for clarity and consistency across papers.

2 Some of these ideas were first explored and written about in Paul Watkins' dissertation, "Soundin' Canaan: Music, Resistance, and Citizenship in African Canadian Poetry" (University of Guelph, 2015).

\section{Works Cited}

Blackman, Toni. "The Cipher, the Circle \& its Wisdom." TEDx. You Tube. 14 May 2013. Web. 15 June 2015.

Caines, Rebecca. "Giving Back Time: Improvisation in Australian Hip-Hop Pedagogy and Performance." Critical Studies in Improvisation / Études critiques en improvisation, 6.2 (2010): 1-19. Web. 15 June 2015.

Coval, Kevin, Quraysh Ali Lansana, and Nate Marshall, eds. The BreakBeat Poets: New American Poetry in the Age of Hip-Hop. Chicago: Haymarket, 2015. Print.

Foytin, Matt A., et al. "Casualties of Lyrical Combat." Symposium About Language and Society (SASLA) VI (1998). University of Texas-Austin. Web. 15 June 2015. <http://studentorgs.utexas.edu/salsa/proceedings/1998.htm\#18>.

Freestyle: The Art of Rhyme. Dir. Kevin Fitzgerald. Organic Films, 2000. DVD.

Giovanni, Nikki. Racism 101. New York: W. Morrow, 1994. Print.

Hill, Marc Lamont. "Representin(g): Negotiating Multiple Roles and Identities in the Field and Behind the Desk." Qualitative Inquiry 12.5 (2006): 926-949. Print.

hooks, bell. Teaching to Transgress: Education as the Practice of Freedom. New York: Routledge, 1994. Print.

“Krip Hop Promotional Video.” YouTube. 24 Feb. 2011. Web. 15 June 2015.

Marsh, Charity. "Bits and Pieces of Truth: Storytelling, Identity, and Hip Hop in Saskatchewan." Perspectives on Contemporary Aboriginal Music in Canada. Ed. Anna Hoefnagels and Beverly Diamond. Montréal: McGillQueen's UP, 2012. 346-371. Print.

Mitchell, Tony. "Introduction: Another Root-Hip-Hop outside the USA." Global Noise: Rap and Hip Hop Outside the USA. Ed. Tony Mitchell. Middletown, CT: Wesleyan UP, 2002. 1-38. Print.

Neal, Mark Anthony. “....A Way out of No Way': Jazz, Hip-Hop and Black Social Improvisation." The Other Side of Nowhere: Jazz, Improvisation, and Communities in Dialogue. Ed. Daniel Fischlin and Ajay Heble. Middletown, CT: Wesleyan UP, 2004. 195-223. Print.

Planas, Roque. "Teaching Hip Hop Illegally Promotes Ethnic Solidarity, Arizona Official Says." Huffington Post. 5 Jan. 2015. Web. 10 Feb. 2015.

Professor Lyrical. “The Transformative Power of Hip Hop.” TEDx. YouTube. 15 May 2014. Web. 15 June 2015. 
Pytlik, Mark. "The Avalanches." Sound on Sound. Nov. 2002. Web. 12 Dec. 2014.

Rice, Jeff. "The 1963 Hip-Hop Machine: Hip-Hop Pedagogy as Composition." College Composition and Communication 54.3 (2003): 453-471. Print.

Rose, Tricia. Black Noise: Rap Music and Black Culture in Contemporary America. London: Wesleyan UP, 2004. Print.

Royal Canadian Mounted Police. Missing and Murdered Aboriginal Women: A National Operational Overview Ottawa: Government of Canada, 2014. Print.

Shepp, Archie. "A Dialogue with Archie Shepp." Interview by Scott Cashman. SPIT: A Journal of the Arts. 10 Dec. 1990. Web. 2 Mar. 2014. <http://www.archieshepp.net/manage content.php?cat id=4\&item id=34>.

Watkins, Paul. "Disruptive Dialogics: Improvised Dissonance in Thelonious Monk and Wu-Tang Clan's 36 Chambers." Critical Studies in Improvisation / Études critiques en improvisation 7.2 (2011): 1-18. Web. 28 Feb. 2015. 